\title{
Energy balancing in ground heat exchanger for heat pump systems - a case study with simulations
}

\author{
Ewelina Stefanowicz ${ }^{1, *}$, and Matgorzata Szulgowska-Zgrzywa ${ }^{1}$ \\ ${ }^{1}$ Wrocław University of Science and Technology, Wybrzeże Stanisława Wyspiańskiego 27, \\ 50-370 Wrocław, Poland
}

\begin{abstract}
The negative impact of systems based on fossil fuel on the environment and the desire to promote sustainable development is increasingly encouraging building owners to invest in renewable energy sources. One of the possibilities of using a renewable energy source located in shallow soil layers is a brine-to-water heat pump. Ground energy can be used for both heating and cooling buildings. This article presents the advantages of balancing the supply and energy consumption from the ground for the large heat pump systems. Authors presented a case study and the simulation of the system operation with different cooling load share vs heating load. This was done on the basis of the analysis of data from several years of measurements from the actual installation as well as the simulation in Earth Energy Designer software. The results of the simulations shows that the most advantageous strategy for the operation of the analysed installation is to provide 50 to $75 \%$ of the cooling load in relation to the heating load.
\end{abstract}

\section{Introduction}

Poland is one of the European countries where air pollution caused by heat sources based on fossil fuel is the largest. The main goal for the Polish energy industry is the sustainable development of renewable energy sources. One of these technologies, using the renewable energy as a heat source is ground-source heat pumps (GSHPs). In Poland, there are still not many GSHPs installations due to high investment costs (in 2017, 5120 GHP installations [1]). The most common type of ground heat exchanger are single U-tube probes. The probes have a depth of 30 to $200 \mathrm{~m}$, and the space between the pipe and the ground is filled with a material based on bentonite with high thermal conductivity. The most commonly used fluid is a $25 \%$ solution of propylene glycol. In practice, other factors are rarely used but there is potential to improve the GSHPs thermal parameters due to the use of nano-fluids or water as described in the previous article [2]. Due to the constantly growing interest in GSHPs, more and more detailed research is being conducted to improve the

\footnotetext{
* Corresponding author: ewelina.stefanowicz@pwr.edu.pl
} 
efficiency of these installations. Incorrect operation of the lower source significantly affects the system efficiency, the coefficient of performance, and thus the system operating costs, extending the investment return time. The impact of an unbalanced GSHPs system on the environment is described in article [3]. It was emphasized that in the case of a building with unbalanced heating and cooling load, the temperature changes around the ground heat exchanger are more and more visible in subsequent years of operation. The use of these systems in buildings with unstable heating and cooling demand and with frequent peak load operation may even lead to freezing of the ground heat exchanger $[4,5]$. Therefore, for large systems, the pilot drilling and the thermal response tests are in practice carried out to determine the effective thermal conductivity of the soil. An overview of existing heat exchange models for GSHPs was presented by Javed et al. [6]. Currently built GSHPs installations have a very diverse heating and cooling load. The research shows that longterm of large-scale, multiple-probes installations operation has less sensitivity to heat exchange disturbances in the lower source, e.g. groundwater flow, under the condition of a balanced heating load [5]. In other publications, researchers conduct an analysis of ground temperature changes based on a numerical model for different thermal loads, borehole configurations and indicate the necessity of analyses for changes in the distance between BHE's in further studies [7,8]. The presented article shows a case study - analysis and simulations of the heat pump's lower source system. Based on the results of the measurements, the model of the lower energy source of the heat pump system in the Earth Energy Designer (EED) was calibrated. This model was used to analyse the operation of this installation with five different share of the cooling and the heating load.

\section{Case study}

\subsection{Description of the installation}

In this article, the authors analysed the operation of the heat pump's lower source installation operating for the heating and cooling system in a commercial and service building. The heat source in the installation is a brine-to-water heat pump cooperating with the lower source consisting of several independent drilling fields. Each field consists of 20 boreholes $130 \mathrm{~m}$ deep each. The pipe in the borehole have a diameter of $40 \times 3.0 \mathrm{~mm}$. The distance between the BHEs is $5.3 \mathrm{~m}$. The heat carrier fluid in the installation is a $25 \%$ propylene glycol solution. The volumetric heat carrier fluid flow rate is $0.15 \mathrm{dm}^{3} / \mathrm{s}$ per borehole. Each borehole's field is connected to a wells. The measurement and analysis results, described below, were carried out for one of the three boreholes groups, i.e. for 40 probes. The thermal load of the soil is about $200 \mathrm{MWh}$ per year for the each group. The cooling load is about $100 \mathrm{MWh}$ per year.

\subsection{Results of the measurements}

In the analysed system the heating energy $\left(\mathrm{Q}_{\mathrm{H}}\right)$ taken from the ground is balanced with the cooling energy $\left(\mathrm{Q}_{\mathrm{C}}\right)$ delivered in the summer. On average, about $40 \%$ of the energy collected in the winter is given back to the ground in a regeneration process realized by the free-cooling (Fig. 1). The system of the heat pumps' low enthalpy energy sources works correctly. Despite the high heating load and a small spacing between boreholes, there is no significant decrease in the average glycol temperature in the following years, the value of this temperature is close to $11^{\circ} \mathrm{C}$ for all three years (Fig. 2). It should be emphasized, that in the first stage of investment implementation the vertical boreholes in this installation were 
intended to be used only as a source of thermal energy. However, due to the very small distances between the boreholes, there was a risk of freezing of the exchanger. In the case of operation of this installation only with a cooling load, the effect of freezing of the lower source would appear in the fifth year of operation, as shown in the Fig. 4. Unbalanced energy consumption from the ground may result in an irreversible environmental effect. The freezing ground around the boreholes will pose a serious threat to the plants and the direction of the natural groundwater flow. It is therefore necessary to properly balance the heating and cooling energy demand. That is why it was decided to change the strategy of exploiting the lower heat source. The analysis of the work of this system for various strategies of the energy balances is shown in the next part of this article.

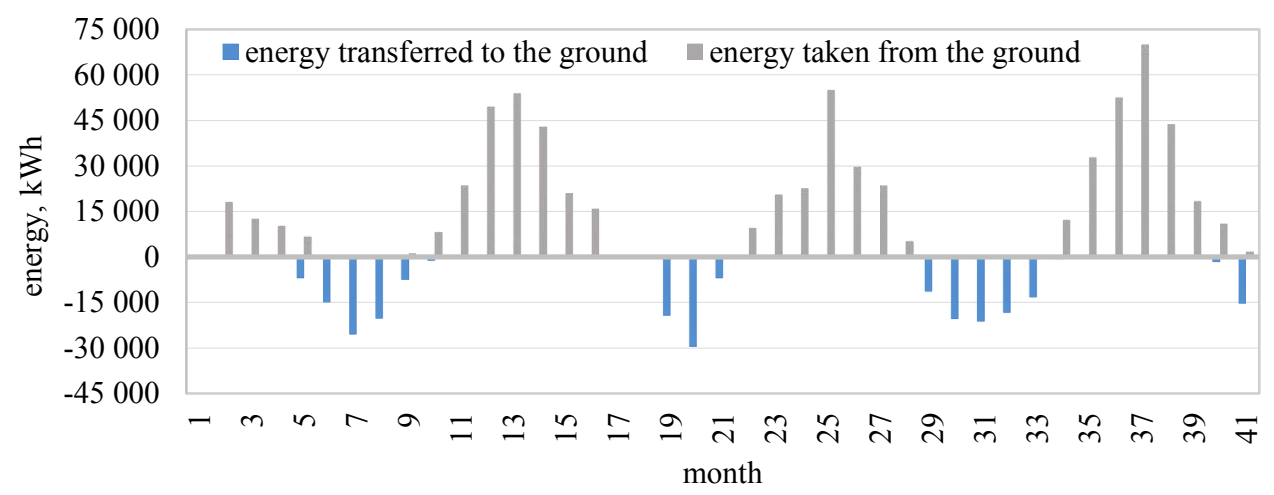

Fig. 1. The heating and cooling load of the building in analysed installation.

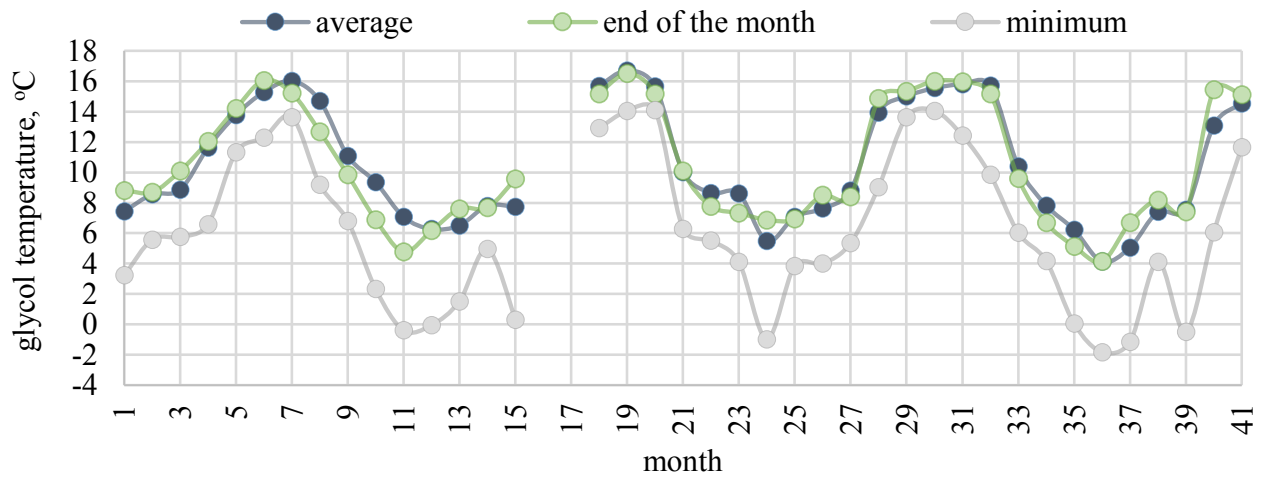

Fig. 2. The average glycol temperature (measurements).

\subsection{Calibration of the lower source model}

The construction of the ground heat exchanger, for the brine-to-water heat pump consisting of more than 10 boreholes, requires a detailed analysis of the ground parameters. In the case of the analysed installation, TRT test were carried out [9]. The results of the calculation, based on the linear infinite source model, provided the information about the effective thermal conductivity coefficient of the ground amounting $1.93 \mathrm{~W} /(\mathrm{mK})$. The undisturbed ground temperature was $10.85^{\circ} \mathrm{C}$. The thermal capacity of the ground, estimated based on the literature, is $1.79 \mathrm{MJ} /\left(\mathrm{m}^{2} \mathrm{~K}\right)$. The model of this installation was prepared in Earth Energy Designer (EED). The model was calibrated based on the ground parameters and the measurements: the heating and cooling load and the glycol temperatures in the first year of system operation. 


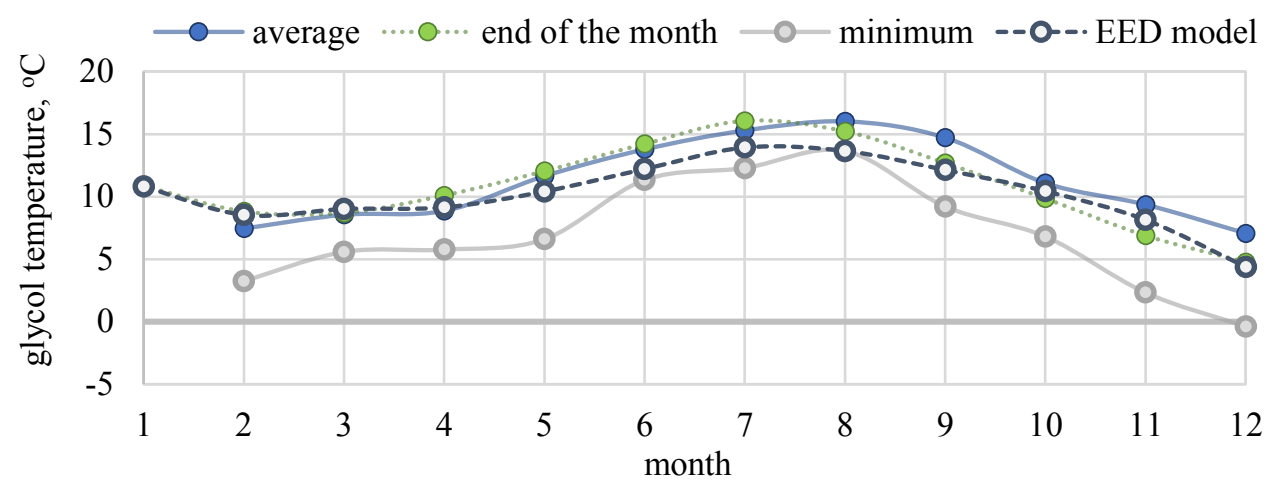

Fig. 3. The average glycol temperature, the simulation and the measurements in the borehole (2014).

The Fig. 3. shows the average heat carrier fluid temperature for the boreholes field (40 probes) during the first year of the system operation and the results of the simulation in the EED program. Earth Energy Designer is a flexible software for designing and analysing the ground heat exchangers installation. It takes into account the boreholes configuration, their technical parameters, ground and heat carrier fluid parameters as well as the heating and cooling load of the installation. The amount of the energy demand can be given in detail (for each month) or for whole year with a percentage breakdown for individual months. The program also allows to specify the time of operation and the first month of installation work. The model in EED reflects very well the actual work of the installation. The average relative uncertainties of the simulation of the average temperature of the heat-carrier fluid $\left(\mathrm{T}_{\mathrm{avg}}\right)$ in individual months are $9 \%$. The model shows the biggest mismatch in May and June (up to 14\%) and in November (18\%).

\section{Analysis of the lower source configuration}

\subsection{Analysis variants}

The purpose of the simulation studies described below is to determine the correct balance of the heating energy $\left(\mathrm{Q}_{\mathrm{H}}\right)$ taken from the ground in winter and the cooling energy $\left(\mathrm{Q}_{\mathrm{C}}\right)$ delivered to the ground during the summer. The following temperatures limits were adopted in these analysis: $0^{\circ} \mathrm{C}$ - is the minimum temperature of the heat carrier fluid in winter (for the protecting against freezing), and $20^{\circ} \mathrm{C}$ - is the maximum temperature of the heat carrier fluid in summer (for the protecting against overheating). Table 1. presents the parameters of subsequent simulations, i.e. the ratio of the heating energy $\left(\mathrm{Q}_{\mathrm{H}}\right)$ to the regeneration energy $\left(Q_{C}\right)$. Table 2 presents the monthly distribution of heating and cooling energy based on data from three years of actual work of the installation.

Table 1. Simulation parameters: the share of the cooling and the heating energy.

\begin{tabular}{|c|c|c|c|c|c|}
\hline Simulation & $\mathbf{1}$ & $\mathbf{2}$ & $\mathbf{3}$ & $\mathbf{4}$ & $\mathbf{5}$ \\
\hline $\mathrm{Q}_{\mathrm{H}}$ & $100 \%$ & $100 \%$ & $100 \%$ & $100 \%$ & $100 \%$ \\
\hline $\mathrm{Q}_{\mathrm{C}}$ & $0 \%$ & $25 \%$ & $50 \%$ & $75 \%$ & $100 \%$ \\
\hline
\end{tabular}

Table 2. Simulation parameters: the monthly energy profile.

\begin{tabular}{|c|c|c|c|c|c|c|c|c|c|c|c|c|}
\hline Month & I & II & III & IV & V & VI & VII & VIII & IX & X & XI & XII \\
\hline $\mathrm{Q}_{\mathrm{H}}$ & $28 \%$ & $15 \%$ & $10 \%$ & $5 \%$ & $2 \%$ & $0 \%$ & $0 \%$ & $0 \%$ & $0 \%$ & $5 \%$ & $13 \%$ & $21 \%$ \\
\hline $\mathrm{Q}_{\mathrm{C}}$ & $0 \%$ & $0 \%$ & $0 \%$ & $0 \%$ & $11 \%$ & $22 \%$ & $27 \%$ & $28 \%$ & $11 \%$ & $1 \%$ & $0 \%$ & $0 \%$ \\
\hline
\end{tabular}


Each simulation was carried out for two variants. In the first variant, the size of the installation corresponded to the size of the actual installation for which the model was prepared. If the analysis of the results indicated an unacceptable temperature of the working medium in subsequent years of operation (beyond the accepted limit values $0^{\circ} \mathrm{C}$ in winter and $20^{\circ} \mathrm{C}$ in summer) then the next stage of the analysis was to increase the distance between boreholes (increase the energy storage volume) so as to maintain the required temperature regime. It should be noted that the problem of limited space available for the installation of a ground heat exchanger is particularly important in the urban area, hence it was decided to discuss this issue. The results of the analyses and the discussion are presented below.

\subsection{Simulation 1 - no cooling load}

The first variant of the analysis presents the operation of the installation with a high heating load and no cooling load. As can be seen in the Fig. 4., the average heat carrier fluid temperatures drop below $0^{\circ} \mathrm{C}$ in the fifth year of system operation for a configuration in which space between the boreholes is $5.3 \mathrm{~m}$. After the $10^{\text {th }}$ year of system operation, the risk of the lower source freezing is significant. In order for the stable operation of the lower source throughout the entire operating period, the distance between the boreholes should be increased at the design and execution phase of the system up to $15 \mathrm{~m}$.
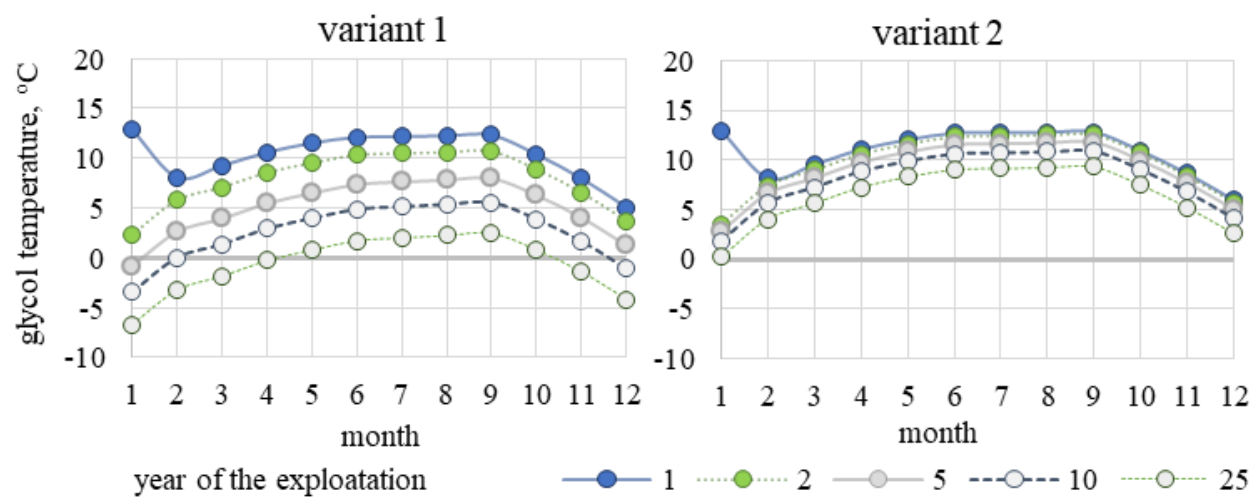

Fig. 4. Results for the simulation 1: variant 1 - distance between the borehole $5.3 \mathrm{~m}$ (area of the exchanger $759 \mathrm{~m}^{2}$ ); variant 2 - distance between the borehole $15 \mathrm{~m}$ (area of the exchanger $6075 \mathrm{~m}^{2}$ ).

The results of this simulation show the effect of lower source self-regeneration. If the distance between the boreholes is maintained, the ground source in the summer period is regenerated, thanks to which the temperature differences between the consecutive years of operation are significantly lower than in the case of the installation in which the distance between boreholes is $5.3 \mathrm{~m}$. In order to enable self-regeneration of the ground source, the area increases from $758.5 \mathrm{~m}^{2}$ to $6075 \mathrm{~m}^{2}$.

\subsection{Simulation $2-25 \%$ cooling load}

The results of the analysis are shown in the Fig. 5. The first variant of the analysis shows the regeneration of the system with a $25 \%$ cooling load in relation to the heating load, with a spacing of $5.3 \mathrm{~m}$ between boreholes. Average fluid temperatures lower than $0^{\circ} \mathrm{C}$ appear in the $10^{\text {th }}$ year of operation. This is a significant improvement over variant 1 in simulation 1. Increasing the distance between probes up to $11.5 \mathrm{~m}$ ensures stable operation of the system 
over the entire exploitation period, the average temperature of the glycol never drops below $0^{\circ} \mathrm{C}$ (variant 2). This results in an increase in the boreholes field's area from $758.5 \mathrm{~m}^{2}$ to $3570.8 \mathrm{~m}^{2}$.
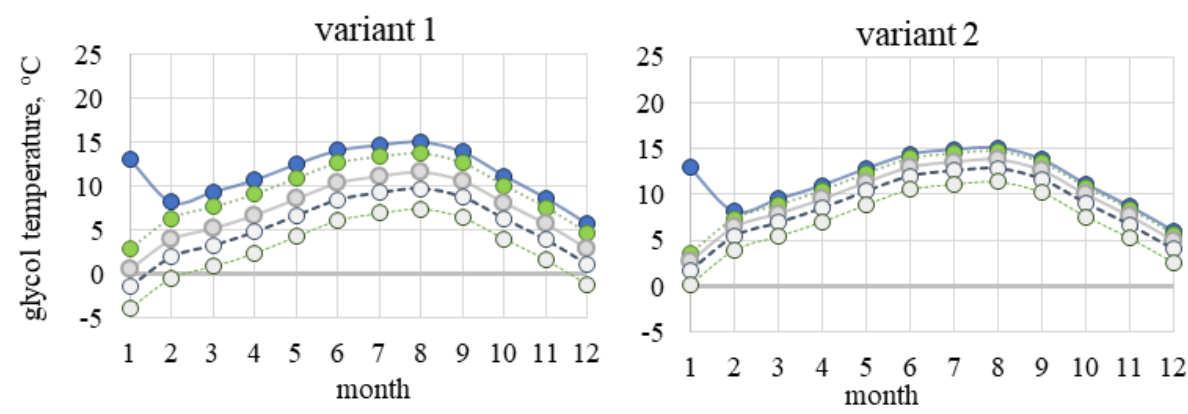

year of the exploatation
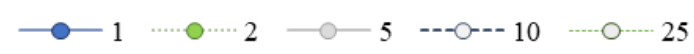

Fig. 5. Results for the simulation 2: variant 1 - distance between the borehole $5.3 \mathrm{~m}$ (area of the exchanger $759 \mathrm{~m}^{2}$ ); variant 2 - distance between the borehole $11.5 \mathrm{~m}$ (area of the exchanger $\left.3571 \mathrm{~m}^{2}\right)$.

\subsection{Simulation $3-50 \%$ cooling load}

The results of the analysis are shown in the Fig. 6. The work of the lower source with the regeneration corresponding to $50 \%$ of the heating load ensures stable operation of this installation. The working fluid temperature below $0{ }^{\circ} \mathrm{C}$ appears only in the $25^{\text {th }}$ year of operation, but the risk of the exchanger freezing at such values is negligible. To ensure the assumptions for the analysis are met (the glycol temperature throughout the analysis period above $0^{\circ} \mathrm{C}$ ) it would be necessary to increase the distance between probes up to $7 \mathrm{~m}$. The surface area of the ground heat exchanger would increase to $1323 \mathrm{~m}^{2}$.
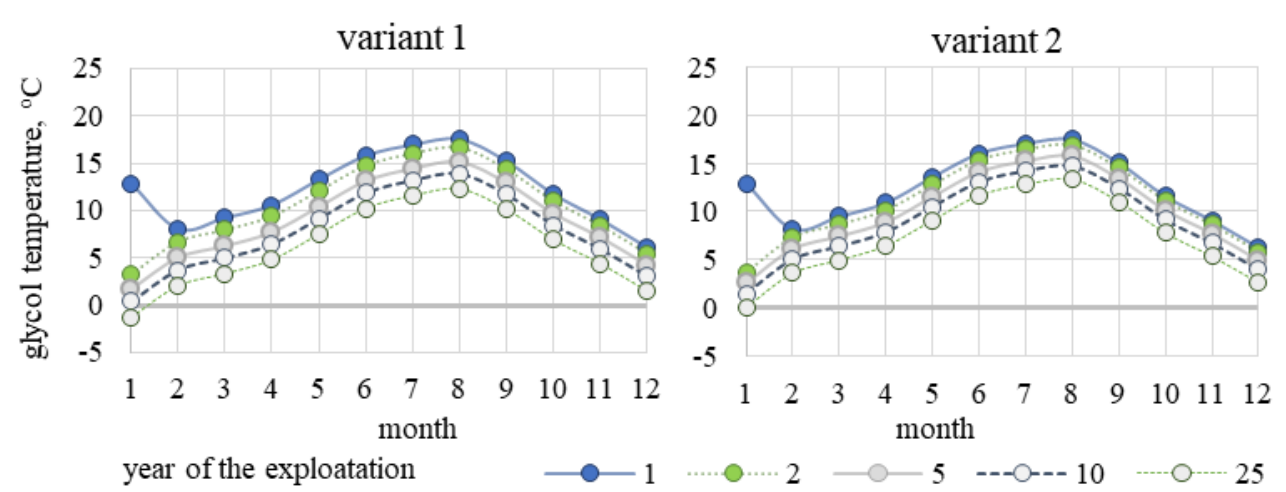

Fig. 6. Results for the simulation 3: variant 1 - distance between the borehole $5.3 \mathrm{~m}$ (area of the exchanger $759 \mathrm{~m}^{2}$ ); variant 2 - distance between the borehole $7 \mathrm{~m}$ (area of the exchanger $1323 \mathrm{~m}^{2}$ ).

\subsection{Simulation $4-75 \%$ cooling load}

The results of the analysis are shown in the Fig. 7. The work of the lower source with the regeneration corresponding to $75 \%$ of the heating load ensures stable operation of the installation. The effect of freezing the lower source does not appear. Theoretically, providing this amount of the regeneration energy to the system give the possibility to 
reduce the distance between the boreholes to $4 \mathrm{~m}$. The surface area of the ground heat exchanger then decreases to $432 \mathrm{~m}^{2}$. This is a very good alternative for the vertical boreholes installations with limited area.

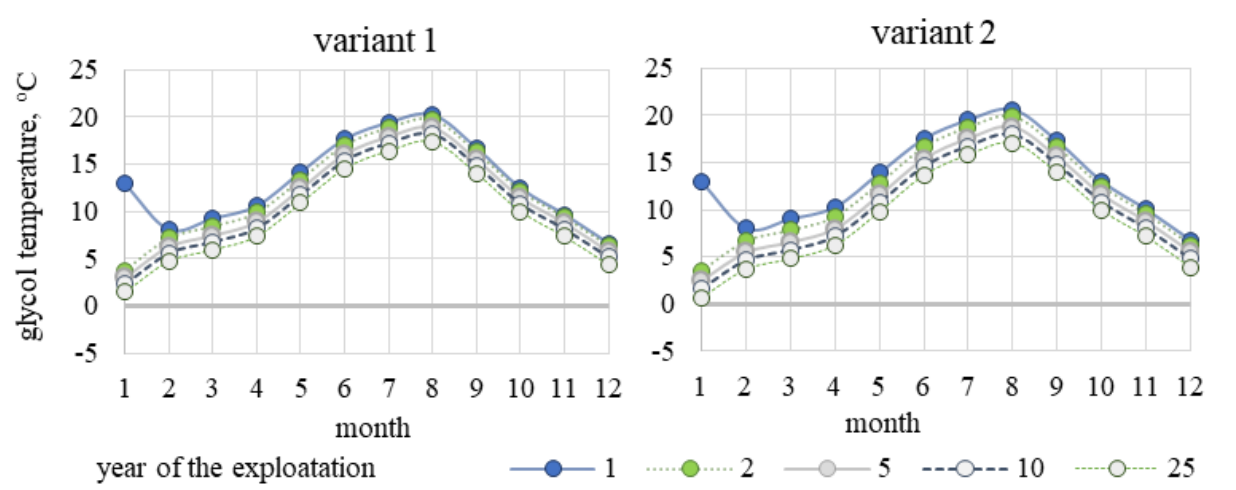

Fig. 7. Results for the simulation 4: variant 1 - distance between the borehole $5.3 \mathrm{~m}$ (area of the exchanger $759 \mathrm{~m}^{2}$ ); variant 2 - distance between the borehole $4 \mathrm{~m}$ (area of the exchanger $432 \mathrm{~m}^{2}$ ).

\subsection{Simulation $5-100 \%$ cooling load}

The results of the analysis are shown in the Fig. 8. Designing systems with the excess regeneration may cause the problem of overheating the ground around BHE in the summer. In the analysed case, the equalization of the energy balance between winter and summer periods causes that the average glycol temperature exceeds $20^{\circ} \mathrm{C}$ and even increasing the distance between boreholes up to $15 \mathrm{~m}$ does not allow to reduce this temperature.

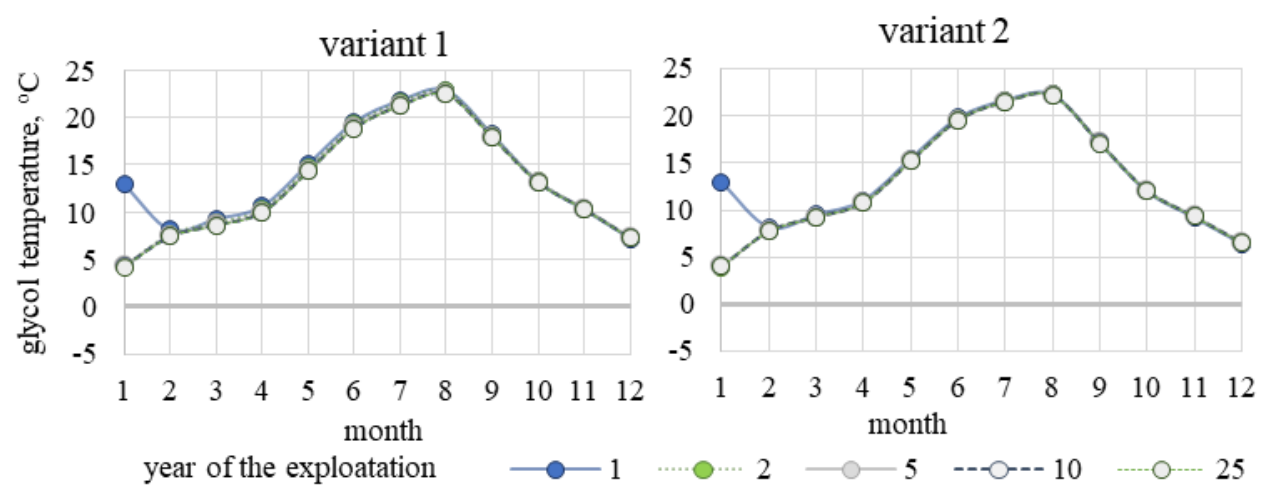

Fig. 8. Results for the simulation 5: variant 1 - distance between the borehole $5.3 \mathrm{~m}$ (area of the exchanger $759 \mathrm{~m}^{2}$ ); variant 2 - distance between the borehole $15 \mathrm{~m}$ (area of the exchanger $6075 \mathrm{~m}^{2}$ ).

It follows that in this case the intensive regeneration of the ground is not recommended. Ground humidity may be reduced and thus the heat exchange may be limited. An increase of the ground temperature around the BHE, especially in cities, where the area designated for ground heat exchanger is small, usually can lead to thermal intrusion and thus the conflict of interests of building owners in urban agglomerations [9]. 


\section{Conclusions}

Ground heat pumps are a very good alternative for heat sources based on fossil fuel. Especially for large installations, it is necessary to design them properly. Starting from the determination of soil parameters through a pilot drilling and the TRT test. An important element is the long-term operation analysis that allows to improve work parameters as shown in publications $[2,10]$. It should be emphasized that in the case of large installations, if an appropriate proportion of heating and cooling energy loads and the size of the ground energy storage are not ensured, it may occur to irreversible environmental effects. Other studies also show the importance of balancing the heat load of the heat pump's lower source installation. Researchers analysed changes in ground temperature for buildings with different heating and cooling energy load (hospital, fast-food restaurant, residence, school) based on a mathematical model [11]. Analyses were also made in terms of the size of the energy store. The research results show the importance of accurate simulations, modelling and designing of lower sources, and indicate the importance of further analyses towards systems with extreme heating and cooling energy needs [12]. In this study, the authors made analyses for a system with a very high energy demand. The analysis criterion was to maintain the working medium temperature in all years of operation above $0^{\circ} \mathrm{C}$ in the winter and $20^{\circ} \mathrm{C}$ in the summer and to indicate the possibility of changing the distance between BHE's. Regeneration of the ground allows reducing the distance between BHE's without adversely affecting the ground temperature. Monitoring and analysis of the system's operation allow to notice disturbing signals and the analysis of the installation's operation allows to develop a long-term strategy for improving the operation of the lower energy source system. Importantly, even if the initial project of the installation did not provide for ground regeneration, it is possible to correct this situation. The most advantageous strategy for the operation of the analysed installation is to provide 50 to $75 \%$ of the cooling load in relation to the heating load. It will allow to improve the work parameters of the installation, i.e. it will ensure stable temperature of the heat carrier fluid both in the heating and cooling season. It will positively affect the heat pump's coefficient of performance, and thus the system operating costs. It should also be emphasized that the cooling energy obtained in the process of free-cooling is energy with very low production costs (related only to the operation of circulation pumps), which has a positive effect on the final building energy.

\section{References}

1. PORT PC, The heat pump market in Poland in 2010-2017. Prospects for the development of the heat pump market by 2030 (on-line: portpc.pl/pdf/raporty/Raport_Rynkowy_PORT_PC_2018.pdf, access: 10 Jan 2019)

2. E. Stefanowicz, M. Szulgowska-Zgrzywa, N. Fidorów-Kaprawy, E3S Web of Conf. 44 (2018)

3. N. Daemi, M. M. Krol, Renewable Energy, 134 (2019)

4. D. Banks, An Introduction to Thermogeology: Ground Source Heating and Cooling (Blackwell, Oxford, 2008)

5. S. E. Dehkordi, R. A. Schincariol, B. Oloffson, Groundwater 53, 558-571 (2014)

6. Javed, P. Pahlen, J. Claesson, Vertical ground heat exchangers : a review of heat flow models (Effstock2009, Stockholm, 2009)

7. X. Zheng, Long-term Effects of Ground Source Heat Pumps on Underground Temperature (Comsol Conf., Boston, 2013) 
8. P. Bayer, M. De Paly, M. Beck, Appl. Energy, 136 (2014)

9. J. D. Spitler, S. E. A. Gehlin, Ren. and Sust. Energ. Rev. 50, 1125 (2009)

10. E. Stefanowicz, N. Fidorów-Kaprawy, E3S Web of Conf. 17 (2017)

11. W. Choi, R. Ooka, Y. Nam, Sust. Cit. and Soc. 38, 429 (2018)

12. Y. L. E. Law, S. B. Dworkin, Appl. Energy, 179 (2016) 